\title{
Comparative Perception of Pharmacovigilance by Physicians versus Paramedical Professions in Ivory Coast
}

\author{
Balayssac Eric ${ }^{1,2}$, Adon Auguste ${ }^{3}$, Tuo Mamadou2 ${ }^{2}$, Ehouman Mocket ${ }^{4}$ \\ ${ }^{1}$ Clinical Pharmacology Service, University Teaching Hospital of Cocody, Abidjan, Côte d'Ivoire \\ ${ }^{2}$ Department of Biochemistry, Physiology and Pharmacology, Training and Research Unit of the Medical Sciences of Abidjan, \\ Felix Houphouet Boigny University, Abidjan, Côte d'Ivoire \\ ${ }^{3}$ Department of General and Digestive Surgery, University Teaching Hospital of Treichville, Abidjan, Côte d'Ivoire \\ ${ }^{4}$ Clinical Research Service, Olopam Pharma and Research and Development, Abidjan, Côte d'Ivoire \\ Email: ebalayssac@yahoo.fr
}

How to cite this paper: Eric, B., Auguste, A., Mamadou, T. and Mocket, E. (2019) Comparative Perception of Pharmacovigilance by Physicians versus Paramedical Professions in Ivory Coast. Pharmacology \& Pharmacy, 10, 416-426.

https://doi.org/10.4236/pp.2019.1010034

Received: September 12, 2019

Accepted: October 8, 2019

Published: October 11, 2019

Copyright $\odot 2019$ by author(s) and Scientific Research Publishing Inc. This work is licensed under the Creative Commons Attribution International License (CC BY 4.0).

http://creativecommons.org/licenses/by/4.0/

\begin{abstract}
Objective: To assess the perception of pharmacovigilance by healthcare professionals practicing at the University Teaching Hospital of Cocody (Ivory Coast) in 2017. Methodology: A descriptive and analytic cross-sectional survey has been conducted in 2017 at the University Teaching Hospital of Cocody. This survey involved a sample of healthcare professionals practicing in 17 services who are prescribing medications and gave their oral consent. Results: A response rate of 54.08\% (106/196) among physicians versus $43.87 \%$ $(86 / 196)$ for the nurses and $27.61 \%(21 / 76)$ for the mid-wives. $57.94 \%(62 / 107)$ of paramedics versus $94.33 \%$ (100/106) of physicians had already heard about pharmacovigilance, during their basic training $(40.18 \%$ of paramedics versus $73.58 \%$ of doctors). However, the main obstacles to the practice of pharmacovigilance were it teaching hours considered insufficient ( $94.39 \%$ of paramedics versus $75.47 \%$ of physicians), the lack of knowledge on the location of the pharmacovigilance unit ( $80.37 \%$ of paramedics versus, $40 \%$ of physicians) and the reporting of the adverse drug reactions to a hierarchical supervisor (60.60\% of paramedics versus $37.25 \%$ of physicians). A regular visit of pharmacovigilance monitors in the hospital services $(34.57 \%$ of paramedics versus $29.24 \%$ of physicians) and the availability of reporting forms (30.84\% of paramedics versus $27.35 \%$ of physicians) could improve the perception of pharmacovigilance by the healthcare professionals. Conclusion: Our investigational survey has highlighted some factors that may influence the perception of pharmacovigilance by the healthcare professionals in Ivory Coast.
\end{abstract}




\section{Keywords}

Perception, Pharmacovigilance, Healthcare Professionals, Hospital

\section{Introduction}

Pharmacovigilance is an essential element of drug safety. Although it is a wellestablished activity in developed countries, it remains non-functional in Ivory Coast despite the existence of regulatory Acts organizing the National Pharmacovigilance System [1] [2] [3] [4]. The drawback has been the reporting of a small number of adverse drug reactions (ADRs) and the lack of reassessment of the benefit-risk ratio of the drugs commercialized in Ivory Coast. In this context, the Clinical Pharmacology Department of the University Teaching Hospital (CHU) of Cocody-Abidjan has implemented a local pharmacovigilance system which collects, evaluates and prevents ADRs at the CHU of Cocody. To be effective, this pharmacovigilance system requires the voluntary declaration of adverse drug reaction (ADR), especially those that are serious and/or unexpected in hospital. In this perspective, the contribution of health actors and the public to voluntary reporting is necessary. Indeed, when a drug is marketed, its safety profile is poorly known in real life as the drug is used in different subsets of people (children, pregnant women...) or different indications or dosages. So, the spontaneous reporting of ADRs by healthcare professionals would assess the safety profile because it is a surveillance method based on the aggregation, at the level of a territory, of ADR cases subsequent to their marketing authorization. In Ivory Coast, few studies have shown that ADRs are poorly reported by healthcare professionals [5] and our study is the first to focus on the perception of pharmacovigilance at Cocody University Hospital Center (CHU). Also, to increase the number of adverse drug reactions (ADRs) notifications we were interested in the perception of the pharmacovigilance by the doctors, nurses and midwives of the CHU of Cocody. These healthcare professionals were targeted on the basis that: on one hand, they represented in 2017 the majority of healthcare personnel at the CHU of Cocody; on the other hand, because of their key role in prescribing, administering and monitoring the drugs.

Our main objective was to assess the perception of pharmacovigilance by the healthcare professionals practicing at the CHU of Cocody in 2017. The secondary objectives were to describe the professional characteristics of the targeted healthcare personnel, to determine their general knowledge on pharmacovigilance, to determine their expectations after reporting adverse drug reactions (ADRs) and to list the measures to be taken to stimulate such notifications.

\section{Method}

From March 15, 2017 to April 05, 2017, we conducted a descriptive and analytical cross-sectional survey in 17 services that prescribed medications (drugs) at the 
CHU of Cocody. The included services were Ophthalmology, Pneumo-phtisiology, Digestive surgery, Urology, Stomatology, Otorhinolaryngology, Neurology, Rheumatology, Paediatric surgery, Traumatology, Gynecology, Hepato-gastroenterology, Intensive care, Paediatrics, X-ray (imaging) and a grouped-emergency services (Paediatric, Surgical, Gynecological and Medical).

\subsection{Study Population}

Our survey targeted the doctors, the nurses and the midwives who were working in those selected services and were prescribing medications (drugs) during 2017. We sampled the healthcare personnel from the administrative list of the $\mathrm{CHU}$ of Cocody. Thus, all the doctors, nurses and midwives assigned to selected services and present during the study period, regardless of their age, sex, nationality, hospital degree, year of professional experience, who gave oral consent were included in the study. On the other hand, the targeted healthcare professionals absent (with the exception of those on night shifts) or unassigned to the selected services at the time of the survey or who did not give consent nor complete the survey form were not included in the study.

\subsection{Study Process}

Firstly, we developed a standardized and anonymized questionnaire in the Department of Clinical Pharmacology from information of the literature reviews. The said questionnaire, after presentation and explanation to our healthcare professionals, was administered by the resident physician of the Clinical Pharmacology Department. In some cases, when the healthcare professionals were not available (lack of time, heavy workload, night shifts, etc.), the questionnaire was given to them for self-administration and then collected the following day by the resident physician of Clinical Pharmacology Department. The questionnaire was previously tested in the Medical and Gynecological emergency services of the $\mathrm{CHU}$ of Cocody in order to improve it. The questionnaire was based on bibliographic data which were adapted to our conditions of practice of medicine, nursing or midwifery. The improved questionnaire included, in the vast majority of cases, open-ended (closed) questions grouped into 5 broad variables, namely:

- The healthcare professionals characteristics (profession, name of the specific hospital services, professional title and year of professional experience);

- General knowledge on pharmacovigilance (level of knowledge, source of information, pharmacovigilance teaching hours in pre-doctoral training, existence and location of a pharmacovigilance unit at the CHU of Cocody, importance given to pharmacovigilance in practice);

- Reporting of adverse drug reactions (existence of ADRs in the hospital services, types of adverse reactions reported, reporting methods, motivation, reasons for non-reporting);

- The expectations of healthcare professionals after reporting an ADR;

- The Measures to boost the reporting of the ADRs. 


\subsection{Statistical Analysis}

The collected data were entered on the EPI info7.4 software and processed by the statistical programme S.P.S.S. 17.0 (Statistical Package for the Social Sciences version 17.0). A Pearson Chi-square test was used to compare the results obtained with a significance level of less than $5 \%$.

\subsection{Ethical Considerations}

In our study, we respected the anonymity of healthcare professionals and no activity of them was disturbed during working hours. In addition, we obtained the oral consent of all the targeted heads of departments (HODs) and a written authorization from the Director of the Medical and Scientific Department of the University Teaching Hospital of Cocody. Finally, no healthcare professional completed the questionnaire under coercion.

\section{Results}

\subsection{Professional Characteristics}

Of the 468 healthcare professionals surveyed (196 doctors, 196 nurses and 76 midwives), the response rate was $54.08 \%$ (106/196) among physicians versus $43.87 \%(86 / 196)$ for the nurses and $27.61 \%(21 / 76)$ for the midwives (Chi2 $=$ $15.813, \mathrm{ddl}=2, \mathrm{p}<0.001$, Table 1$)$. These healthcare professionals are working mainly in the medical and surgical services (Table 1) and had a professional experience ranging from 1 to 10 years in most cases (Table 2).

\subsection{General Knowledge on Pharmacovigilance}

In our study, $94.33 \%(100 / 106)$ of physicians versus $57.94 \%(62 / 107)$ of paramedics (i.e. nurses and midwives) had significantly (Chi2 $=38.73$, ddl $=1, \mathrm{p}<$ 0.001 ) already heard about pharmacovigilance (Table 2), mainly during their basic training ( $73.58 \%$ of physicians versus $40.18 \%$ of paramedics; Chi $2=24.206$ ), $\mathrm{ddl}=1, \mathrm{p}<0.001)$ with the pharmacovigilance teaching hours deemed sufficient by only $24.52 \%(26 / 106)$ of physicians versus $5.60 \%(6 / 107)$ of paramedics (Chi2 $=14.932, \mathrm{ddl}=1 ; \mathrm{p}<0.001)$. In addition, $48.11 \%(51 / 106)$ of physicians versus $16.63 \%(21 / 107)$ of paramedics were aware of the existence of the pharmacovigilance unit (Chi2 $=19.312, \mathrm{ddl}=1, \mathrm{p}<0.001)$. This unit was correctly identified and located to the Clinical Pharmacology Department by $90.19 \%$ of physicians versus $47.61 \%$ of paramedics. In addition, $54.71 \%$ (58/106) of the physicians versus $48.59 \%(52 / 107)$ of the paramedics considered pharmacovigilance very important in their daily practices ( $(\mathrm{Khi} 2=0.798, \mathrm{ddl}=1, \mathrm{p}<0.30)$ as shown in Table 2.

\subsection{Reporting of Adverse Effects}

In our survey, $68.86 \%(73 / 106)$ of the responding physicians versus $59.81 \%$ $(64 / 107)$ of the paramedics indicated to have come across an adverse event (Chi2 $=1.903, \mathrm{ddl}=1, \mathrm{p}<0.10)$, mostly ADRs (Table 3 ). These events were reported 
Table 1. Distribution of health professionals by services.

\begin{tabular}{|c|c|c|c|c|c|c|}
\hline \multirow[b]{2}{*}{ Services } & \multicolumn{2}{|c|}{ Nurses $(n=196)$} & \multicolumn{2}{|c|}{ Midwives $(\mathrm{n}=76)$} & \multicolumn{2}{|c|}{ Physicians $(\mathrm{n}=196)$} \\
\hline & Responses & Percentages & Responses & Percentages & Responses & Percentages \\
\hline Medicine $^{* *}$ & $36 / 60$ & $60 \%$ & $02 / 05$ & $40 \%$ & $44 / 68$ & $64.7 \%$ \\
\hline Surgery ${ }^{* * *}$ & $33 / 64$ & $51.56 \%$ & $04 / 07$ & $57.14 \%$ & $38 / 38$ & $100 \%$ \\
\hline Gynecology & $00 / 00$ & $00 \%$ & $12 / 36$ & $33,33 \%$ & $12 / 20$ & $60 \%$ \\
\hline Paediatric & $06 / 17$ & $35.29 \%$ & $02 / 27$ & $0.07 \%$ & $09 / 45$ & $20 \%$ \\
\hline $\begin{array}{c}\text { Emergency } \\
\text { service* }^{*}\end{array}$ & $11 / 55$ & $20 \%$ & $01 / 01$ & $100 \%$ & $3 / 25$ & $12 \%$ \\
\hline Total & 86 & $43.87 \%$ & 21 & $27.61 \%$ & 106 & $54.08 \%$ \\
\hline
\end{tabular}

${ }^{\star}$ Emergency service: Emergencies of Medicine, Surgery, Gynecology and Paediatrics; ${ }^{*}$ Medicine: Pneumophtisiology, intensive care unit, Rheumatology, Gastroenterology, Neurology; ${ }^{* *}$ Surgery: Traumatology, Digestive Surgery, Urology, Ophthalmology, OtoRhino Laryngology, Stomatology, Paediatric Surgery.

by $69.9 \%(51 / 73)$ of physicians versus $76.74 \%(33 / 43)$ of paramedics $(\mathrm{Chi} 2=$ $0.641, \mathrm{ddl}=1, \mathrm{p}<0.30)$, mainly to an hierarchical supervisor $(37.25 \%$ of physicians versus $60.60 \%$ of paramedics). The main causes of non-reporting by physicians and paramedics were the already known factor, the frequent occurrence or the benign nature of adverse events (Table 3 ).

\subsection{Expectations and Measures to Stimulate Spontaneous Notification}

After a report of the adverse drug reactions, a feedback (Table IV) was expected by $41.50 \%(44 / 106)$ of physicians versus $28.97 \%$ (31/107) of paramedics (Chi2 $=$ 3.669; $\mathrm{ddl}=1, \mathrm{p}<0.05)$. Also, the second expectation of the physicians $(\mathrm{n}=32$, $30.18 \%)$ represented by a specific code of conduct was the main expectation for the paramedics ( $\mathrm{n}=40,37.38 \%)$ (Chi2 $=1.232, \mathrm{ddl}=1 ; \mathrm{p}<0.20)$. Nonetheless, the healthcare professionals surveyed recommended essentially a regular visit by the pharmacovigilance monitors in the prescribing services $(29.24 \%$ of physicians versus $31.57 \%$ of the nurses and midwives) in order to stimulate the reporting of adverse drug reactions (Chi2 $=0.697, \mathrm{ddl}=1, \mathrm{p}<0.30$ ). The availability of reporting forms was secondarily reported in $27.35 \%$ (29/106) of physicians versus $30.84 \%(33 / 107)$ of the nurses and midwives (Chi2 $=0.312$, ddl $=1, \mathrm{p}<$ $0.50)$ as shown in Table 4.

\section{Discussion}

Our survey was conducted among 106 doctors, 86 nurses and 21 midwives practicing at the CHU of Cocody in 2017. It was the first Ivorian study which described the perception of pharmacovigilance at the CHU of Cocody. It had some limitations mainly related to the availability of the healthcare professionals and the method of data collection (self-administered questionnaire or administered by the registrar of the Clinical Pharmacology Department). Apart from these limitations, the information gathered had made it possible to analyze the data 
Table 2. General knowledge on pharmacovigilance.

\begin{tabular}{|c|c|c|c|}
\hline Modalities & Paramedical staff (\%) & Physicians (\%) & $P$ values \\
\hline \multicolumn{4}{|c|}{ Already heard about pharmacovigilance } \\
\hline Yes & $62(57.94)$ & $100(94.33)$ & \multirow{3}{*}{$<0.001$} \\
\hline No & $45(42.06)$ & $6(5.66)$ & \\
\hline Total & 107 & 106 & \\
\hline \multicolumn{4}{|c|}{ Source of information } \\
\hline Initial formation & $43(40.18)$ & $78(73.58)$ & \multirow{8}{*}{$<0.001$} \\
\hline Colleague & $11(10.28)$ & $8(7.54)$ & \\
\hline Media & $4(3.73)$ & $10(9.43)$ & \\
\hline Physician & $2(1.86)$ & 00 & \\
\hline Book & $1(0.93)$ & 00 & \\
\hline Training workshop & $1(0.93)$ & $4(3.77)$ & \\
\hline No answers & $45(42.05)$ & $6(5.66)$ & \\
\hline Total & 107 & 106 & \\
\hline \multicolumn{4}{|c|}{ Schedule volume of pharmacovigilance } \\
\hline Enough & $6(5.60)$ & $26(24.5)$ & \multirow{3}{*}{$<0.001$} \\
\hline Not enough & $101(94.3)$ & $80(75.4)$ & \\
\hline Total & 107 & 106 & \\
\hline \multicolumn{4}{|c|}{ Existence of a pharmacovigilance unit at Cocody } \\
\hline \multicolumn{4}{|c|}{ Teaching Hospital } \\
\hline Yes & $21(19.63)$ & $51(48.11)$ & \multirow{4}{*}{$<0.001$} \\
\hline No & $86(80.37)$ & $37(34.90)$ & \\
\hline No answers & 00 & $18(16.98)$ & \\
\hline Total & 107 & 106 & \\
\hline \multicolumn{4}{|c|}{ Importance of pharmacovigilance } \\
\hline Not important & $4(3.73)$ & 00 & \multirow{6}{*}{$<0.30$} \\
\hline Little important & $12(11.21)$ & $6(5.66)$ & \\
\hline Important & $23(21.49)$ & $42(39.62)$ & \\
\hline Very important & $52(48.59)$ & $58(54.71)$ & \\
\hline No answers & $16(14.95)$ & 00 & \\
\hline Total & 107 & 106 & \\
\hline \multicolumn{4}{|c|}{ Seniority in the profession } \\
\hline $0-5$ years & $31(28.97)$ & $42(39.62)$ & \\
\hline $6-10$ years & $23(21.49)$ & $27(25.47)$ & \\
\hline $11-15$ years & $17(15.88)$ & $13(12.26)$ & \\
\hline$>15$ years & $36(33.64)$ & $24(22.64)$ & \\
\hline Total & 107 & 106 & \\
\hline
\end{tabular}


Table 3. Reports of adverse events.

\begin{tabular}{|c|c|c|c|}
\hline Modalities & Paramedical staff (\%) & Physicians (\%) & $P$ values \\
\hline & \multicolumn{3}{|c|}{ Have you ever experienced an adverse event? } \\
\hline Yes & $43(40.18)$ & $73(68.86)$ & \\
\hline No & $64(59.81)$ & $33(31.13)$ & $<0.001$ \\
\hline \multirow[t]{2}{*}{ Total } & 107 & 106 & \\
\hline & \multicolumn{3}{|c|}{ Adverse event related to } \\
\hline Drug & $32(74.41)$ & $65(89.04)$ & \\
\hline Equipment & $6(13.95)$ & $6(8.21)$ & \\
\hline Reagent & $3(6.97)$ & 0 & $<0.02$ \\
\hline Labile blood product & $2(4.65)$ & $2(2.73)$ & \\
\hline \multirow[t]{2}{*}{ Total } & 43 & 73 & \\
\hline & \multicolumn{3}{|c|}{ Was an adverse event declared? } \\
\hline Yes & $33(76.74)$ & $51(69.86)$ & \\
\hline No & $10(23.25)$ & $22(30.13)$ & $<0.30$ \\
\hline \multirow[t]{2}{*}{ Total } & 43 & 73 & \\
\hline & \multicolumn{3}{|c|}{ If yes, did you report it? } \\
\hline To a superior & $20(60.60)$ & $19(37.25)$ & \\
\hline To the staff meeting & $6(18.18)$ & $9(17.64)$ & \\
\hline In the patient's file & $5(15.15)$ & $8(15.68)$ & \\
\hline To a colleague & $1(3.03)$ & 00 & \\
\hline To the drugstore & $1(3.03)$ & $2(3.92)$ & $<0.02$ \\
\hline A the service of Pharmacology & 00 & $10(19.60)$ & \\
\hline At the National Transfusion Center & 00 & $1(1.96)$ & \\
\hline To pharmaceutical companies & 00 & $2(3.92)$ & \\
\hline \multirow[t]{2}{*}{ Total } & 33 & 51 & \\
\hline & \multicolumn{3}{|c|}{ If no, reasons for non-declaration } \\
\hline Fréquent event & $4(44.44)$ & $6(27.27)$ & \\
\hline Benign event & $2(22.22)$ & $3(13.63)$ & \\
\hline Known event & $1(11.11)$ & $10(45.45)$ & \\
\hline Not important event & $1(11.11)$ & $1(4.54)$ & \\
\hline Lack of time & 00 & $2(9.09)$ & \\
\hline No reason & $1(11.11)$ & 00 & \\
\hline Total & 09 & 22 & \\
\hline
\end{tabular}


Table 4. Expectations after reporting an adverse event and steps to be taken to stimulate reporting.

\begin{tabular}{ccc}
\hline Variables & Paramedical staff & Physicians \\
\hline Feedback & Expectations after reporting & \\
\hline A withdrawal from marketing & $31(28.97)$ & $44(41.50)$ \\
A health alert & $13(12.14)$ & $4(3.77)$ \\
Precise management & $15(14.01)$ & $15(14.15)$ \\
A modification of the instructions & $40(37.38)$ & $32(30.18)$ \\
Unspecified & $8(7.47)$ & $10(9.43)$ \\
Total & 00 & $1(0.94)$ \\
Creation of a website & 107 & 106 \\
Availability of declaration forms & $11(10.28)$ & $19(17.92)$ \\
Regulars visits of the animators in the services & $33(30.84)$ & $29(27.35)$ \\
Feedback with precise management & $37(34.57)$ & $31(29.24)$ \\
Newsletter to prescribers & $26(24.29)$ & $26(24.52)$ \\
Total & 00 & $1(0.94)$ \\
\hline
\end{tabular}

relating to the socio-professional characteristics, the general knowledge on pharmacovigilance, the reporting of the ADRs and lastly, the expectations and measures to stimulate the spontaneous notification.

\subsection{Socio-Professional Characteristics}

In our survey, the physician's response rate $(54.08 \%)$ was significantly different from that of nurses $(43.87 \%)$ and of the midwives $(27.61 \%)(\mathrm{p}<0.001)$. This rate (54.08\%) was higher than that of the 2006 Ivorian survey (31.4\%) conducted on a random sample of 500 practitioners extracted from the database of the approved drug prescribers of the "Mutuelle Générale des Fonctionnaires de Côte d'Ivoire (MUGEF-CI)" [5]. In contrast, the response rate of the targeted healthcare professionals in our study was lower than that reported in the literature [6]-[13]. This could be explained by the methodological differences and by the level, variables according to countries, and healthcare professional's awareness on pharmacovigilance. Moreover, in our work the physicians response was neither influenced by the service in which they work $(\mathrm{p}=0.593)$ nor their seniority in the profession ( $p=0.309$ ); which was not the case for the nurses and midwives regarding their working service $(\mathrm{p}<0.001)$ and years of experience $(\mathrm{p}<0.01)$.

\subsection{General Knowledge of Pharmacovigilance}

In our study, most paramedics $(\mathrm{n}=62 ; 57.94 \%)$ and physicians $(\mathrm{n}=100 ; 94.33 \%)$ had previously heard about pharmacovigilance $(\mathrm{p}<0.001)$ primarily through 
their basic training (Table 2). Indeed, this training was the main source of information in $40.18 \%$ of the paramedics versus $73.58 \%$ of the physicians $(\mathrm{p}<$ 0.001). However, the volume of teaching hours of the pharmacovigilance module during the basic training was considered sufficient only by $5.60 \%(6 / 107)$ the paramedics versus $24.5 \%(26 / 106)$ of the physicians $(\mathrm{p}<0.001)$. And so, any increase in the teaching hours of pharmacovigilance would be desirable in the basic training of healthcare professionals in Côte d'Ivoire. Similarly, a need for continuing education in pharmacovigilance was suggested in our survey because only $19.63 \%$ (21/107) of the paramedics versus $48.11 \%$ (51/106) of the physicians knew of the existence of a pharmacovigilance unit at the CHU of Cocody ( $\mathrm{p}<$ 0.001 ). The lack of knowledge of this unit (especially by $80.37 \%$ of the paramedics) was an obsticle to the reporting of the adverse drug reactions and therefore a factor in favor of a poor perception on pharmacovigilance. Our situation was comparable to that described in a Saudi study [7], as well as in an Indian study [8]. In Saudi Arabia, $12.1 \%$ of doctors did not know the term "pharmacovigilance" and $62.2 \%$ of healthcare professionals did not know of the existence of a national pharmacovigilance center [7]. Similarly, in an Indian study [8], 77\% of doctors had already heard about pharmacovigilance but only $6.6 \%$ could located the national pharmacovigilance center. An awareness of the practice of pharmacovigilance and continuous training could correct these results. In our study, apart from this lack of knowledge and the low teaching hours of pharmacovigilance, other factors of under-reporting of adverse drug reactions were highlighted.

\subsection{Reporting of Adverse Drug Reactions}

These included the non-compliance with the regulatory reporting procedures [1] [4] and the already known factor (déjà-vu) or the frequent occurence of the adverse drug reactions. In our study, the paramedical personnel $(n=43,40.18 \%)$ and the physicians ( $n=73,68.86 \%$ ) who had previously come across an adverse event, mainly linked to a drug (Table 3), for the most part, reported the events to a hierarchical supervisor $(60.60 \%$ of the paramedics versus $37.25 \%$ of the physicians, $\mathrm{p}<0.02$ ). This was not in line with the Ivorian regulatory Act which oblige all healthcare professional to report an adverse reaction that could be due to a drug or health product to the National Pharmacovigilance Center [1] [4]. Since the latter only exists by the ministerial decree creating it [4], all adverse drug reactions occurring at the CHU of Cocody should have been reported to the Clinical Pharmacology Department. In addition, the main reason for non-reporting among the paramedics $(\mathrm{n}=9)$ and the physicians $(\mathrm{n}=$ 22) was the frequent occurrence (4/9) or the already known (déjà-vu) factor $(10 / 22)$ of the adverse drug reactions respectively. This was also not justified because all adverse drug reactions should be reported, especially those that are unexpected or serious [1]. These results were comparable to those found in several studies [6]-[13]. 


\subsection{Expectations and Measures to Stimulate the Reporting Process}

In our survey (Table 4), the expectations following a report of an adverse drug reaction by the paramedics $(n=107)$ and or the physicians $(n=106)$ were primarily a feedback and a specific code of conduct (actions) $(66,33 \%$ of the paramedics versus $71.69 \%$ of the physicians). These two main expectations, if they were systematically addressed through a personalized newsletter sent to the healthcare professionals would increase the reporting of the adverse drug reactions at the CHU of Cocody. Apart from the feedback, the healthcare professionals in our study recommended essentially a regular visit of pharmacovigilance monitors in hospital services (34.57\% of the paramedical versus $29.24 \%$ of the physicians, $\mathrm{p}<0.30)$ and the availability of the reporting forms $(30.84 \%$ of the paramedics versus $27.35 \%$ of the physicians, $\mathrm{p}<0.50)$. These measures were comparable to those reported in other studies [6]-[13] and reflected the involvement of healthcare professionals to improve the reporting of the adverse drug reactions at the CHU of Cocody.

\section{Conclusion}

Our investigation survey has revealed some factors that could explain the under-reporting of the adverse drug reactions. The main obstacles to the practice of pharmacovigilance were it teaching hours considered insufficient, the lack of knowledge on the location of the pharmacovigilance unit and the reporting of the adverse drug reactions to a hierarchical supervisor. A regular visit of pharmacovigilance monitors in the hospital services and the availability of reporting forms could improve the perception of pharmacovigilance by the healthcare professionals. In addition, a multicenter study with a larger staff size would refine the factors influencing the perception of pharmacovigilance by health professionals.

\section{Conflicts of Interest}

The authors declare no conflicts of interest regarding the publication of this paper.

\section{References}

[1] Ministry of Health and Public Hygiene (2010) Act No. 210/MSHP/CAB of 24 November 2010 Modifying the Decree No. 16MSHP/CAB of 10 February 2009 Establishing, Organizing and Operating the National System of Pharmacovigilance.

[2] Ministry of Health and Public Hygiene (2010) Act No. 211/MSHP/CAB of November 24, 2010 Modifying the Decree No. 249 MSP. DSPH of November 18, 1988 Establishing a National Commission of Pharmacovigilance.

[3] Ministry of Health and Public Hygiene (2010) Act No. 212/MSHP/CAB of 24 November 2010 Establishing, Allocating, Organizing the Operation of the National Monitoring Committee of the Strategic Plan 2011-2015 for Pharmacovigilance in Côte d'Ivoire. 
[4] Ministry of Health and Public Hygiene (2013) Act No. 070 MSLS/CAB of May 14, 2013, Establishing, Organizing, Allocating and Operating the Health Project Called the National Center for Pharmacovigilance.

[5] Die-Kacou, H., Kamagaté, M. and Daubrey, T. (2007) Knowledge of the Pharmacovigilance and Reporting of Adverse Effects by Ivorian Practitioners. Journal of Epidemiology and Public Health, 55, 18. https://doi.org/10.1016/j.respe.2007.07.048

[6] Vural, F., Ciftci, S. and Vural, B. (2014) The Knowledge, Attitude and Behaviours of Nurses about Pharmacovigilance, Adverse Drug Reaction and Adverse Event Reporting in a State Hospital. Northern Clinics of Ístanbul, 1, 147-152. https://doi.org/10.14744/nci.2014.41636

[7] Noor, B.A. (2016) Healthcare Professionals' Awareness and Knowledge of Adverse Drug Reactions and Pharmacovigilance. Saudi Medical Journal, 37, 1359-1364. https://doi.org/10.15537/smj.2016.12.17059

[8] Bhagavathula, A.S., Elnour, A.A., Jamshed, S.Q. and Shehab, A. (2016) Health Professionals' Knowledge, Attitudes and Practices about Pharmacovigilance in India: A Systematic Review and Meta-Analysis. PLOS ONE, 11, e0152221.

https://doi.org/10.1371/journal.pone.0152221

[9] Nde, F., Fah, A.B.D., Simo, F.A. and Wouessidjewe, D. (2015) State of Knowledge of Cameroonian Drug Prescribers on Pharmacovigilance. Pan African Medical Journal, 20, 70. https://doi.org/10.11604/pamj.2015.20.70.3873

[10] De Angelis, A., Giusti, A., Colaceci, S., Vellone, E. and Alvaro, R. (2015) Nurses' Reporting of Suspect Adverse Drug Reactions: A Mixed-Methods Study. Annali dell Istituto Superiore di Sanità, 51, 277-283.

[11] Mendes, M.J.I., Polonia, J.M., Figueiras, A.G., Costa Santos, C.M. and Herdeiro, M.T. (2016) Nurses' Attitudes and Spontaneous Adverse Drug Reaction Reporting: A Case-Control Study in Portugal. Journal of Nursing Management, 24, 409-416. https://doi.org/10.1111/jonm.12337

[12] Fadare, J.O., Enwere, O.O., Afolabi, A.O., Chedi, B. and Musa, A. (2011) Knowledge, Attitude and Practice of Adverse Drug Reaction Reporting among Healthcare Workers in a Tertiary Centre in Northern Nigeria. Tropical Journal of Pharmaceutical Research, 10, 235-242. https://doi.org/10.4314/tjpr.v10i3.4

[13] Li, Q., Zhang, S.M., Chen, H.T., Fang, S.P., Yu, X., Liu, D., et al. (2014) Awareness and Attitudes of Healthcare Professionals in Wuhan, China to the Reporting of Adverse Drug Reactions. Chinese Medical Journal, 117, 856-861. 